\title{
ENGLISH IN THE 2010S - GETTING UP CLOSE AND PERSONAL
}

\author{
John Jamieson*
}

The following is a personal enquiry into how our view of the world may be affected in some very specific ways by the language we speak, and more particularly the way we write, with specific reference to consensus and norms. These musings have arisen over many years of working as a translator, and are based on my interactions as an English speaker with texts in many European, and to a lesser extent, Polynesian languages. The English I speak of here is mainly my English, perhaps my idiolect as a 58-year-old New Zealander. Some of the preferences I mention may be less applicable in British English, for example, but every native speaker's idiolect reflects something of the language as a whole, and I hope my readers will identify linguistically with some of what I am saying. I hope I may be forgiven for writing rather colloquially and in the first person. This choice is entirely consistent with my subject-matter, however, as will become evident.

The initial problem that generated these ideas has been the translation into English of a number of words and phrases expressing value judgments based on some sort of implied consensus rather than purely individual opinion. One such word is the German einwandfrei, which appears frequently in employment references, or sales material for technical products, for example. An "Einwand" is basically an "objection", and "frei" denotes "free of", and accordingly English translations range from "unobjectionable" to "impeccable". The question is, how can one word, in the same context, cover such a wide continuum of meaning?

Before attempting to answer that question (or come up with a halfway decent translation), I would like to mention some other awkward cases of a similar phenomenon, where the seemingly obvious equivalent in English conveys quite the wrong impression. For example, cognates of "adequate" in French and numerous other European languages simply mean "suitable" or "fit for purpose", yet in English the implication of "barely adequate" interferes with effective communication of this idea. Similarly, cognates of "presentable" might describe a prestigious piece of real estate, for example, in many parts of Europe, particularly Germany and Scandinavia, but smack of "barely passing muster" in English. "Expedient" is another case in point - in Slavonic and

* John Jamieson studied French at Otago University and Russian at Victoria, and has been a professional translator of non-fiction texts for over 30 years. 
Germanic languages this concept refers to an advisable or appropriate course of action, yet in English it carries a nuance of cold-blooded calculation and heartlessness that puts the word off limits in a technical document, for example. And "perfect" is no better - a lease in French or Spanish may require the tenant to keep the garden in "perfect" condition, yet in English this seems like a little too much to ask.

What is going on here? I believe these translation difficulties reflect a fundamental difference in point of view between our languages, whereby a contrast between my and other people's opinion is implied in English but not elsewhere. The "barely adequate" nuance can be interpreted as "okay in other people's eyes, but not very good as far as I am concerned". And "presentable" perhaps implies "other people might present it, but I wouldn't". Along the same lines, "expedient" might suggest that "it should be done, but I couldn't bring myself to do it". So to return to einwandfrei, the translation "unobjectionable" is clearly at the "adequate", "damning with faint praise" end of the spectrum, whereas "impeccable" is a personal guarantee of excellence, almost beyond the bounds of any human frailty. The solution for the translator might be something like "perfectly satisfactory", but the problem is that einwandfrei suggests the existence of a collectively perceived standard. The person's conduct has been such that one (you and/or I and/or everybody) cannot object to it. Similarly, one can confidently present a nicely turned-out seaside property. So the problem may be that in English we are no longer sure of who one is.

This, too, is a problem familiar to many translators working into English. An old stumbling block for us is the phrase "as is well known", as a literal translation of Russian "kak izvestno", German "wie bekannt", and equivalents elsewhere all across Europe. Yet English speakers find this awkward. Something is felt to be missing, possibly an implied semantic subject - who is doing the knowing here?

The answer to this question is seen most clearly in the French version of this phrase: "comme on sait". So the implied subject is one, yet we cannot say that in English. Once again, we do not know who one is.

English is rather different from other languages here. Our pronoun one has a very restricted range of uses. In terms of style it is rather elevated, to the extent that many speakers - including me - do not use it at all. And in terms of meaning the reference is to me and some implied others, and it often refers to what should be the case, rather than is the case.

Most other Germanic languages have an equivalent pronoun, "man" ("men" in Dutch), and of course the French have "on", which they passed to us in the 15th century. Yet "man" is much more widely used in those languages, and across a wider range of meanings, than English "one". At the end of Ibsen's Hedda Gabler, for example, following the heroine's suicide, the magistrate says "man 
gjør icke det". The Penguin Classics translation ${ }^{1}$ has "one doesn't do that kind of thing", but the intended meaning is closer to "people don't do such things", as another anonymous translation I have puts it. ${ }^{2}$ So Norwegian man can also refer to third persons without the first person, and can be indicative as opposed to the more optative tone in English. English "one" is also more restricted than its counterparts elsewhere in that it is seldom used in written language, yet nor is it freely available in colloquial spoken language. French "on" is widely used, in both colloquial spoken and formal written language. It too operates as a first person plus pronoun, but can just as easily refer to what one did (we did) as what one does (we should do).

There is no obvious lexical equivalent of man in Slavonic languages and Romance languages other than French, but the same slot is filled with passive, impersonal and reflexive expressions. Examples include "como se sabe" for "as is well-known" in Spanish, and "mozhno" and "nado" in Russian, for "one can" and "one must". And in Finnish the mood described as passive is semantically cognate with "man" in Germanic.

The availability of man and similar structures has the effect of blurring the distinctions between first person singular and other persons, between me and not me. It may therefore seem logical that during its evolution, while losing this blurring feature, English has also added some verbal tenses to make similar distinctions particularly clear. For example the present continuous "I am doing" or "she is going" largely has the effect of emphasising that this is happening for me now, as opposed to the general "I do" or "she goes", which is more objective, with no reference to me, here and now. This distinction is generally absent elsewhere in Europe, apart from Spanish.

And similarly the perfect/aorist distinction is used systematically in English to indicate whether the action specifically impacts on me, the speaker, or not. While the same two tenses are widely available elsewhere, the distinction between them does not appear to operate in the same way.

Another instance where English is forced to distinguish between subjective and objective experience, as opposed to the situation in other European languages, becomes evident when translating such words as French "bonheur" and "malheur" - meaning either "happiness/unhappiness" (subjective) or "good fortune/ill fortune" (objective).

So at this stage my hypothesis is that the absence of "man" as a smoother of distinctions between persons in English is reflected in the presence of a number of mandatory choices the English speaker is required to make, as compared with the greater flexibility elsewhere. This offers a convincing explanation for the difficulty of translating the expressions cited at the beginning of this essay into English, implying an opinion that is or could be collectively held. I believe that the

1 Henrik lbsen (translated by Una Ellis-Fermor) Hedda Gabler and Other Plays (Penguin, Harmondsworth, 1952) at 364.

2 Henrik Ibsen Eleven Plays of Henrik Ibsen (Random House, New York, 1950). 
collective entity required to hold these opinions, embracing both me and not-me, is simply not available in modern English.

I see this clear split between me and not me as part of a trend towards an increasingly individual focus that is probably occurring in all languages, but is proceeding at a particularly rapid pace in English. I lack the expertise required to demonstrate this, but in any event this does seem to be a continuing trend in English that has some important consequences for many aspects of linguistic usage, particularly in some formal contexts, and especially, I will suggest, in the language of law.

As a different take on the same problem, I recently suggested elsewhere ${ }^{3}$ that non-fiction texts are a mixture of three narrative modes, which can be distinguished in terms of the implied persons (in the grammatical sense) involved in the communication act. I call these modes the communication, sermon and lecture modes.

Conversation mode refers to an I-to-you communication, which creates a relatively narrow we, comprising the speaker and interlocutors. The features of a communication in this mode - for example "Waiter, there is a fly in my soup" - include the following: there is a clearly defined speaker and interlocutor, the focus is on a real, specific and concrete, here-and-now experience, at individual rather than collective level. And the statement is also easily refutable, clearly either true or false. In terms of linguistic features, I-to-you communications of this type are characterised by concrete nouns, clear marking of any repetition of known information, not much use of subjunctive tenses, and shorter rather than longer sentences. There is a strong taboo on self-reference in the third person, and in English, vocabulary of Anglo-Saxon origin is likely to be preferred to words taken from, say, French or Latin.

The community of we created by a sermon refers to all of us. This is a consensus-building exercise - think of the sentence "we are gathered here together...". The speaker is clearly defined in one sense, but is only standing at the front of the church or in the pulpit as a representative of his/her particular profession, and the audience can be a very diverse group, with many different reasons for being there. The communication will include a lot of generic references; any concrete or specific concepts may be images representing some more general truth. This is collective rather than individual communication, and the form of truth being conveyed will not be easily disprovable. At the micro-level, abstract nouns and subjunctives may well abound and repetitions will be frequent. Self-reference in the third person is often acceptable.

The information presented in a lecture aspires to objective truth in a general, even universal sense. The we community in this case can perhaps be defined as people in general. A physical law or a historical fact is true without reference to the speaker or listener. The linguistic means used are characterised by a mix of concrete and abstract nouns, but the concrete nouns will often be

3 AUSIT 2010 - Proceedings of the "Synergise" Biennial National Conference of the Australian Institute of Interpreters and Translators (Cambridge Scholars Publishing, forthcoming). 
representative of their class rather than referring to a specific object. Subjunctives will be relatively rare, but other devices typical of the sermon, such as repetition, may well be used.

So we have three modes of verbal communication, generating ever wider communities of we: conversation mode, relating to a small group; sermon mode, relating to all of us (in this room); and lecture mode, relating to people in general, all of us (on the planet).

Each of these communities also has its own kind of truth - literal and directly related to the participants for a conversation (with very high penalties for lying); aspirational and not necessarily including all participants for the sermon; and general/universal, but without reference to individual participants for the lecture.

A crucial point to remember is that the presence of a clearly defined first and second person in conversation mode tends to be matched by concrete, specific subject-matter, for instance, the third person. And similarly, the more collective identity of the players in the sermon and lecture situations is mirrored in the more generic and abstract nature of the subject matter.

The situation becomes more interesting when speech becomes text and we begin to translate from one language into another. A written text typically has elements of all three modes, but the correspondence between specific linguistic means and narrative mode differs between languages.

In languages other than English, a phrase can be both conversation and sermon or lecture, since the man entity is able to cover all the persons involved in these modes. In English, however, the writer or reader has to make a choice, and there is a clear and increasing preference for conversation mode utterances, on the basis that the other narrative stances are distinguished from the I/you mode, which tends to carry the implication that the statement has nothing to do with you or me.

When I suggested recently in a presentation that statements such as "love is a many-splendored thing" or "patience is a virtue" are now seen as sermon or lecture sentiments devoid of immediate personal impact, for example, I was upbraided by a Māori listener, who made it very clear that such proverbs and adages certainly do carry a strong personal impact in Māori. So in English, the me versus non-me split may be reflected in a tendency to see sermon or lecture mode discourse as irrelevant or uninteresting.

Now, this could be part of the reason for the emergence of at least two forms of discourse that have become widely used over recent decades, particularly in English-speaking countries.

The first of these is assertive language, where rather than saying "I hate you" or "you ruined my electoral campaign", it is preferable to say "I don't like it when you do things like that", or "the way I see it is that your actions have had a negative effect on my electoral campaign". This mode of discourse is certainly reflected in many written communications from government organisations to the community, with an additional propensity to speak in the third person: "The Government believes that New Zealanders should eat more apples", or some such. The speaker and the 
addressees of the message would appear to be clearly identified, and this is regarded as good, effective communication.

Yet in a sense this might also be analysed as a sermon being made to look more like a conversation. In fact the message is addressed to a fairly loosely defined audience (New Zealanders), exactly as in the sermon situation referred to earlier, and the intention is to create consensus and change collective behaviour.

By making the persons explicit (the Government and New Zealanders), the message has perhaps been made more immediate. Yet as noted earlier, the naming of both speaker and addressees, the semantic first and second persons, in the grammatical third person, is not characteristic of conversation mode communication, and indeed is to some extent taboo, so the statement may still lack impact.

So what happens when the brochure containing this excellent sentiment is translated into Māori? What kind of communication community is created in this situation? The first aspect to consider is the impact of writing in a particular language, in this case Māori. Given the status of English as a widely-used language all around the world, the mere fact of writing in English says very little about the relationship between the writer and the reader. This situation is dramatically different in a less widely used language. For example, Finnish "kotimainen", literally "home country" as an adjective, really refers to "our home country as people who read and speak this language", in other words, Finland. Similarly the word "Ukraine" literally means "in the country", but denotes "in our territory", "here", "this country". Similar situations apply elsewhere across Europe.

Thus the mere fact of communicating in Māori implicitly places both the speaker and addressee within a fairly specific community of those who speak and understand the language, so rather than shying away from the collective we, or sermon mode, it could well be that embracing it, and simply saying "me kai āporo tātou" ("let's eat apples, let's get apple-eating") could be a much more effective approach to getting the message across.

So the implication is that our perceptions of what constitutes assertive language, or even plain language, could reflect the specific nature of English, and the rules for effective communication in other languages could be quite different. Indeed, when I put these ideas to my colleagues at a conference I was delighted to hear a highly-skilled Cook Island Māori translator say that she had been wanting to use tātou for years, but didn't think she was "allowed to"!

This raises the fascinating possibility that the movement towards assertive language could have been prompted by changes naturally taking place in English in any event, as well as by deliberate choices of policy and approach.

Spin can also be understood as a sermon dressed up in conversation clothing. The aim of this kind of communication in the political and corporate sphere is generally to create a consensus, but to have any impact, the message now has to be presented in conversation mode. The problem is that 
the statements made in this mode are supposed to be falsifiable - they can only be right if capable of being proved wrong - yet in the mind of the would-be persuader there is only one truth, only one predefined right answer. So where the preacher may draw the response "I don't agree with that" without being accused of lying, the spin merchant runs a high risk of being exposed as a liar, thereby negating the impact that was sought in the first place.

The increasing preference for conversation mode in written communication in English may be generating a trend that impacts more directly on language and the law: the loss of generic reference. Law is not generally about what a specific person or even organisation may or may not do, but rather how a class of person or organisation is to act.

Yet the ability of English to operate on this level may be under threat. For example, a book published in New Zealand in the 1940s was entitled "English in the primary school". Most English speakers would now say "English in primary schools", I suspect. Yet "le lycee" and "l'université" are still perfectly serviceable expressions for higher secondary and tertiary education in French, for example.

Other examples abound. When I asked a Hungarian friend what was the book he was reading, he said the title was "The Church and the Sect". "The church" still has generic force in English, but "the sect" immediately prompts the question "which one?".

Or for that matter, consider the first line of the Hungarian national anthem, "Isten, áldd meg a magyart!". The translation normally given is "God bless the Hungarian", but this does not sound quite right in contemporary English. The problem is that "God bless" is a rhetorical expression, clearly in sermon mode for our purposes. This is our hope, both the speaker's and the listeners' - that God will give His blessing - and yet "the Hungarian" suggests a specific Hungarian, a flesh-andblood individual known to the speaker but not (yet) to the person addressed. Another problem is that the sentiment "God bless the Hungarian", expressed in English, suggests that the speaker is not Hungarian him- or herself because of the ban on self-reference in the third person.

Accordingly a more idiomatic translation could be "God bless our Hungarian nation!". The use of our makes the sermon mode explicit, and the collective (and abstract nation) also helps restore the message to the right domain.

Or think of a magazine article entitled "Der nеue Mann", comparing the profile of film stars such as Humphrey Bogart and John Wayne to Tom Cruise and Brad Pitt. "The new man" in English would prompt the question - "oh, who's that then?", in other words, the perceived reference would be to a specific male individual that the author is telling the reader about. The intended narrative is much more generic, further away from the conversational end of my spectrum - so "A new kind of hero" was a possible version in English. Note the transforms: definite to indefinite article, generic "kind of" to make the noun less concrete, and a noun with epithetical force ("hero"). 
The final issue to be considered here is that of changes in the perception of modal verbs used to convey obligation. In particular, there has been a shift in the perceived ownership of the English verb must over the centuries. In Pride and Prejudice, Mr Darcy, speaking of the required attributes for womanhood, notes that "all this she must possess", before continuing the list. Apart from the issue of she, which might now have to refer to a real, live, individual woman, the must does not imply any authority on his part, yet this would be the meaning now. Rather than personally dictating what a woman must be like, he is expressing (what be believes to be) a generally held opinion on the matter - what one (or man) thinks. In other words must would appear to have moved from sermon mode to conversation mode - must has become an I-to-you transaction in English, but possibly not elsewhere.

This was brought home a few years ago in a draft set of guidelines for New Zealand translators prepared by the New Zealand Society of Translators and Interpreters (Inc) for its members. ${ }^{4}$ The committee drafting the guidelines comprised a German native speaker and a French native speaker, and the text duly began "All translators must follow these guidelines". The must drew a sturdy yeoman response from many of the native English speaker members, on the basis "how dare they tell us what to do? Who do they think they are?", and so on. Yet the intended meaning was something nearer to "these guidelines are intended to apply to all translators".

This is why should has emerged as a modal verb in government communications of the kind mentioned earlier, product manuals and many other texts providing instructions. According to this argument, should occupies the semantic niche created by the shift of must to denoting a personally imposed obligation.

This reminds me of an issue that used to bother my colleagues and me when reviewing translations of brochures into a range of Polynesian languages. We could never explain to our translators what the nuance of should was, or find an equivalent phrase in their languages. I now realise that there was no solution simply because there was no problem. The obligation conveyed by, say, "tatau" in Samoan is not personally owned or imposed, and therefore does not have to be smoothed or softened with any equivalent of "should". My friends more closely involved in the law have also mentioned the decline in the use of shall in this context. ${ }^{5}$

4 Now published as New Zealand Society of Translators and Interpreters "NZSTI Guidelines: For the Translation of Official and Legal Documents" (2005) Publications <www.nzsti.org>.

5 AC Thornton in Legislative Drafting (3rd ed, Butterworths, London, 1987) addressed the use of shall and may but not must. Undoubtedly, at that time, must would have been viewed as inappropriate and informal. "Shall" (see Legislative Drafting, ibid at 90) was identified as ambiguous, and its main use as a model denoting obligation; may as indicating a discretion. In 2011, New Zealand legislative practice is to use must for obligation, "may" for discretion, and shall or will to indicate the future. This represents a significant change in New Zealand drafting practice in recent decades. 
In summary, I believe the English language is becoming less able to deal with the formulation of consensual judgments and norms, not, or not only, because of cultural changes, but because of deepseated changes taking place within the language. I have suggested some relationships between these trends and grammatical structures that have been fundamental to English for several centuries, which indicates that rather than just following and reflecting the culture of its speakers, the English language may be directing the performance rather more than we might like to think. 
